\title{
GEOTECHNICAL CASE HISTORY FOR SINKHOLE INVESTIGATION AND STABILIZATION METHODS ALONG A HIGH PRESSURE PETROLEUM PIPELINE
}

\author{
John T. Pusey, Jr., and John M. Caccese, P.E. \\ Earth Engineering Inc., 115 W. Germantown Pk., Ste. 200, East Norriton, Pennsylvania 19401 USA, \\ johnp@earthengineering.com,johnc@earthengineering.com
}

\begin{abstract}
Installation of underground pipelines through unpopulated land situated over pinnacled carbonate bedrock can lead to the development of sinkholes. The formation of sinkholes beneath buried pipelines has the potential of damaging the pipeline and more importantly causing hazardous environmental incidents.
\end{abstract}

This paper presents a case history at a site where significant sinkholes developed within and adjacent to a 400 foot (112 meters) long section of high pressure petroleum pipeline right-of-way that crosses under a local creek in Plymouth Meeting, Pennsylvania.

Various geophysical investigation techniques consisting of microgravity, multi-channel analysis of surface waves (MASW), and two dimensional electrical resistivity testing were performed in addition to confirmatory testing borings to effectively evaluate the subsurface conditions at the site. Three options were considered as a solution to the active sinkholes present within the pipeline rightof-way. These options include: 1) subsurface grouting within the right-of-way 2) structurally supporting the pipeline on a deep foundation system or 3) relocating the pipeline to a less sinkhole prone portion of an adjacent property. Following the investigation process, relocating the pipeline in conjunction with pre-installation ground improvements via subsurface grouting represented the most cost-effective, lowest risk solution at the site.

\section{Introduction}

In January 2009 a sinkhole developed below an active petroleum pipeline that crossed under a local creek in Plymouth Meeting, Pennsylvania. Upon initial discovery, it was reported that the sinkhole measured approximately 9 feet ( 3 meters) in diameter by 9 feet ( 3 meters) in depth causing the pipeline to be unsupported across a portion of the open void. Representatives of the pipeline company filled in the sinkhole with various materials that ranged from tree stumps to geotextile filter fabric and well-graded aggregates as a temporary solution to the problem. Following the temporary backfill measures, the owner recognized the severity of the problem and the need for the expertise of a geotechnical engineering firm.

Initially, a feasibility study was conducted to determine the most cost-effective and best long term solution at the site. The options considered include: 1) subsurface grouting within the right-of-way 2) structurally supporting the pipeline on a deep foundation system or 3 ) relocating the pipeline to a less sinkhole prone portion of an adjacent property.

The first step in the study was to perform a site reconnaissance and a stereographic aerial photograph review. Due to the site being primarily wooded, inconclusive results were found from the aerial photograph review. During the site reconnaissance, the streambed was dry on each side of the pipeline crossing. The stream bed remained dry for approximately 500 to 600 yards (457 to 549 meters) upstream of the sinkhole at the pipeline crossing. Further inspection revealed a large sinkhole had created a disappearing stream condition upstream of the pipeline crossing. Photograph 1 shows the large sinkhole upstream of the pipeline crossing.

The overall topography within the pipeline right-of-way slopes gently to moderately downwards toward the creek and sinkhole locations. Photograph 2 shows the area of study within the pipeline right-of-way.

The overall topography within the pipeline right-of-way slopes gently to moderately downwards toward the creek and sinkhole locations. Photograph 2 shows the area of study within the pipeline right-of-way.

\section{Project Description and Background}

During low flow conditions, the creek water disappears into the upstream sinkhole leaving the downstream side dry. During periods of steady rainfall, storm water 


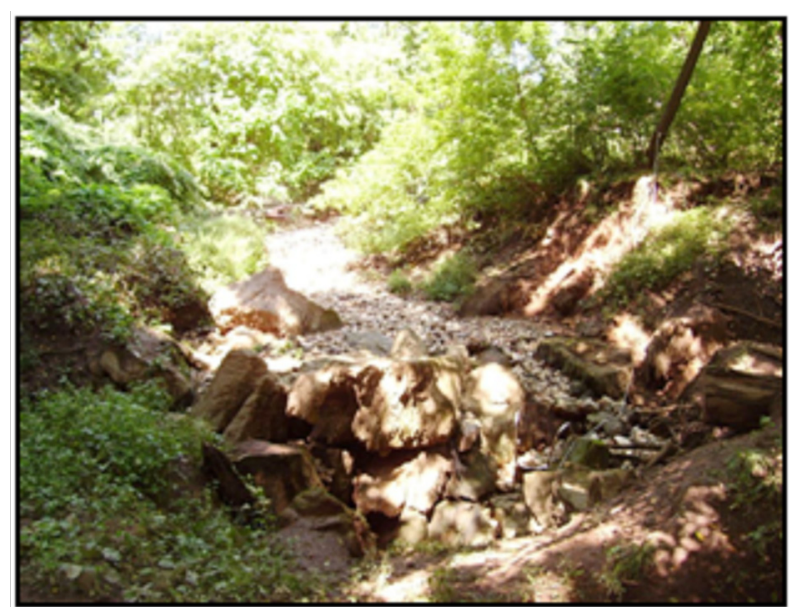

Photograph 1. Sinkhole within creek bed.

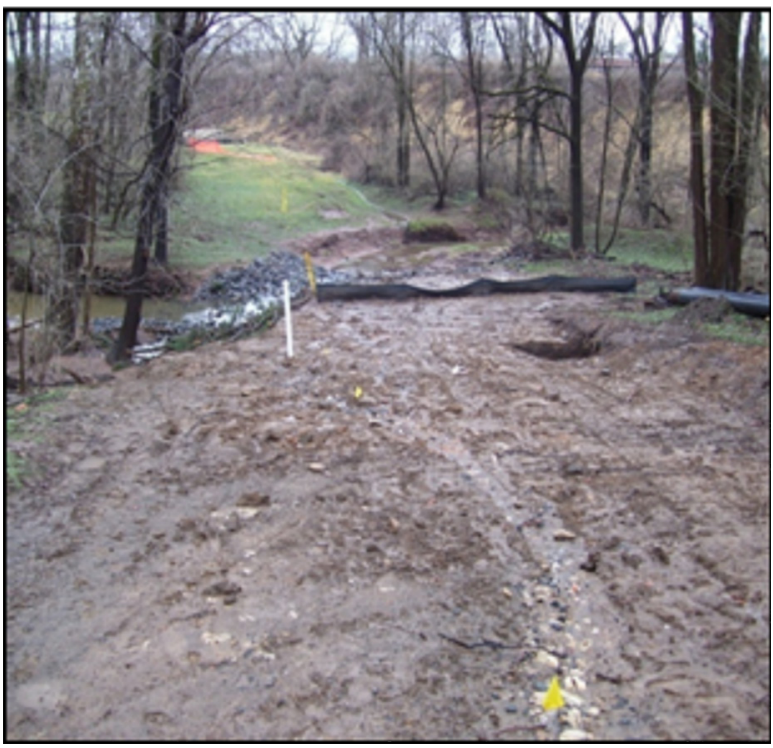

Photograph 2. Pipeline right-of way crossing local creek.

fills the large sinkhole upstream and continues to flow down past the pipeline crossing. Numerous additional sinkholes are present on the western bank of the stream between the disappearing stream location and the sinkhole at the pipeline crossing. At the conclusion of the first phase of the investigation, it was evident that the immediate region is highly active and warranted further means of investigation.

Two separate geophysical investigation methods were initially performed within the referenced section of pipeline right-of-way and portions of the streambed on each side of the right-of-way. The first method, microgravity, provides a broad interpretation of the subsurface conditions and the second method, multi- channel analysis of surface waves (MASW), provides a linear profile of the subsurface below the pipeline. The combination of the geophysical methods provides a relatively accurate depiction of the subsurface conditions within the area of study.

The microgravity investigation provides spatial coverage of the investigation area. "Broad areas of higher gravity indicate relatively shallow rock (potential pinnacles) and broad areas of lower gravity indicate relatively deeper rock (voids). In microgravity surveying, fractures and faults are typically observed as linear low gravity anomalies because the fractured rock tends to be less dense than the bounding non-fractured rock" (Lee, 2012, email communication).

The study conducted at the site consisted of recording microgravity readings in a 10 foot ( 3 meters) by 10 foot ( 3 meters) grid pattern. Features such as voids in the bedrock and/or weak soil conditions appeared in sharp contrast to dense soil or bedrock. In addition, potential faults and fracture traces were also generated from the microgravity investigation. The results of the microgravity readings at each grid station are plotted in color and a microgravity contour map is generated to provide a clear interpretation of the subsurface conditions to the viewer. Figure 1 shows the results of the microgravity investigation.

The results of the microgravity investigation clearly depict that subsurface conditions in the vicinity of the 2009 sinkhole location are highly variable with dense, shallow rock on the eastern and southern side of the creek and less dense, deeper overburden soils on the north and west side of the creek. Interpretation of the survey also revealed the presence of a potential fault that trends in a general northwest-southeast lineation. The fault extends between the pipeline and the northern edge of the pipeline right-of-way where the deeper overburden exists. Consequently, a majority of the sinkhole activity is on the north side of the fault. Two parallel fractures also exist in line with the creek and perpendicular to the fault line. It is significant to note that sinkholes have an increased risk of development in proximity to the intersection of fractures and faults in the underlying bedrock. Accordingly, at this site, sinkhole locations coincide with the location of intersecting fractures and faults. Further exacerbating sinkhole activity is that the topography generally slopes downwards in all directions 

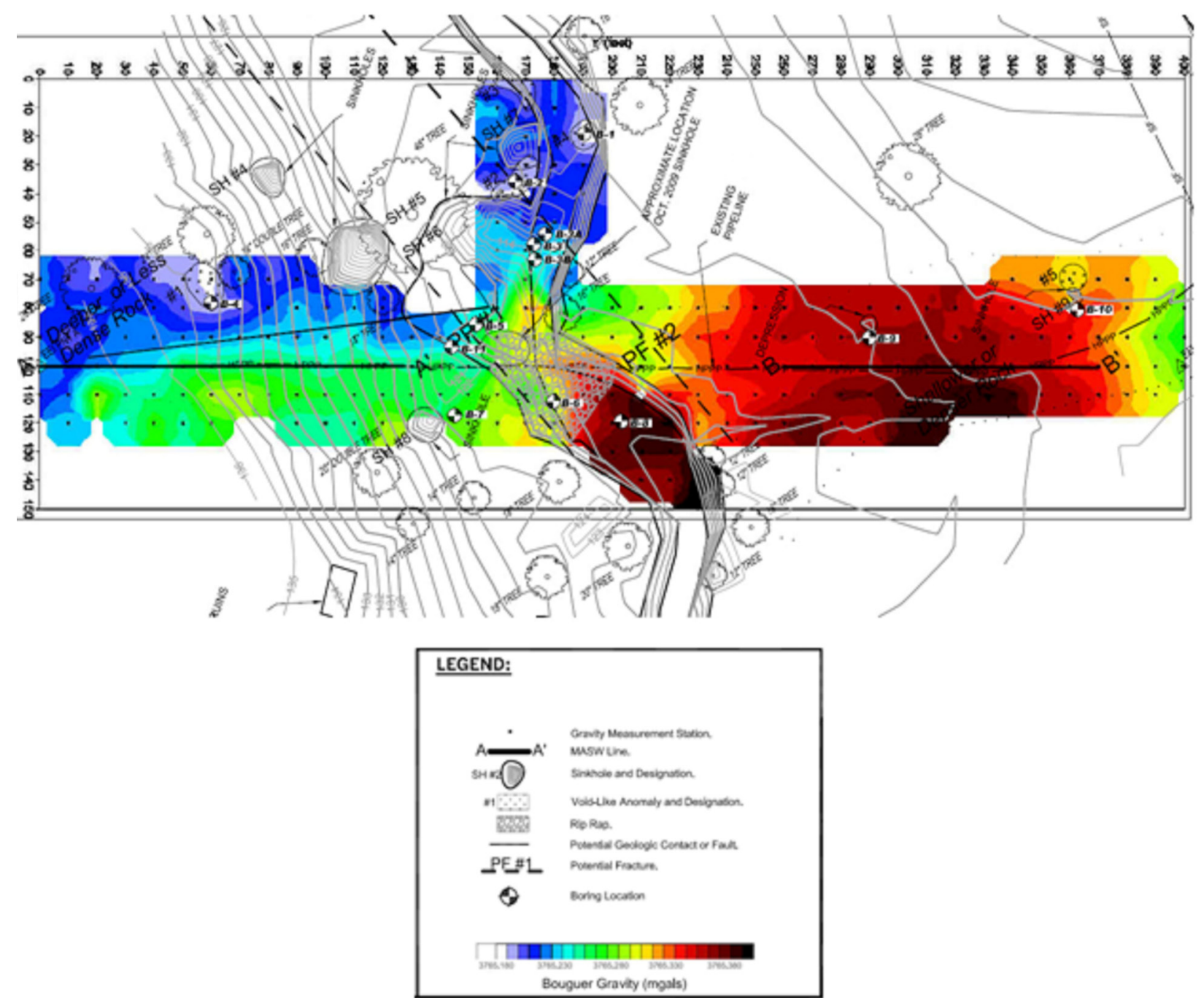

Figure 1. Microgravity results.

toward sinkhole areas. The sinkholes are also at an apparent transition location between the shallow dense rock on the south and east side of the pipeline and deeper and less dense rock on the north and west side. Competent bedrock tends to be a barrier to stormwater infiltration such that during a period of surficial stormwater flow over the sinkhole area, the infiltrating stormwater deflects off the shallow, pinnacled rock surface and carries away loose soil and rock material to accelerate the sinkhole activity (Lee, 2010).

Following the microgravity investigation, the secondary geophysical method consisting of MASW was performed adjacent to the existing pipeline. The MASW method was used to provide a linear geophysical profile of subsurface conditions directly below the pipeline. The MASW could not be completed within the stream channel where rip rap was present. The MASW profile was generated from the interpretation of shear wave velocities generated by striking a plate attached to the ground. Geophones, spaced along selected intervals of the array record shear wave velocities as function of distance from strike point. From this data, material properties and depth to bedrock were estimated (Lee, 2010). The results are presented in Figure 2. After the completion of the geophysical investigations, 13 test borings were performed in proximity to open sinkholes, over anomalous subsurface conditions identified in the geophysical surveys, and where dense shallow bedrock was interpreted to exist. The intent of the test borings was to verify the conditions found in the geophysical investigations. Standard Penetration Tests (SPT) were performed at regular intervals throughout the borings until auger refusal was achieved. Following refusal 


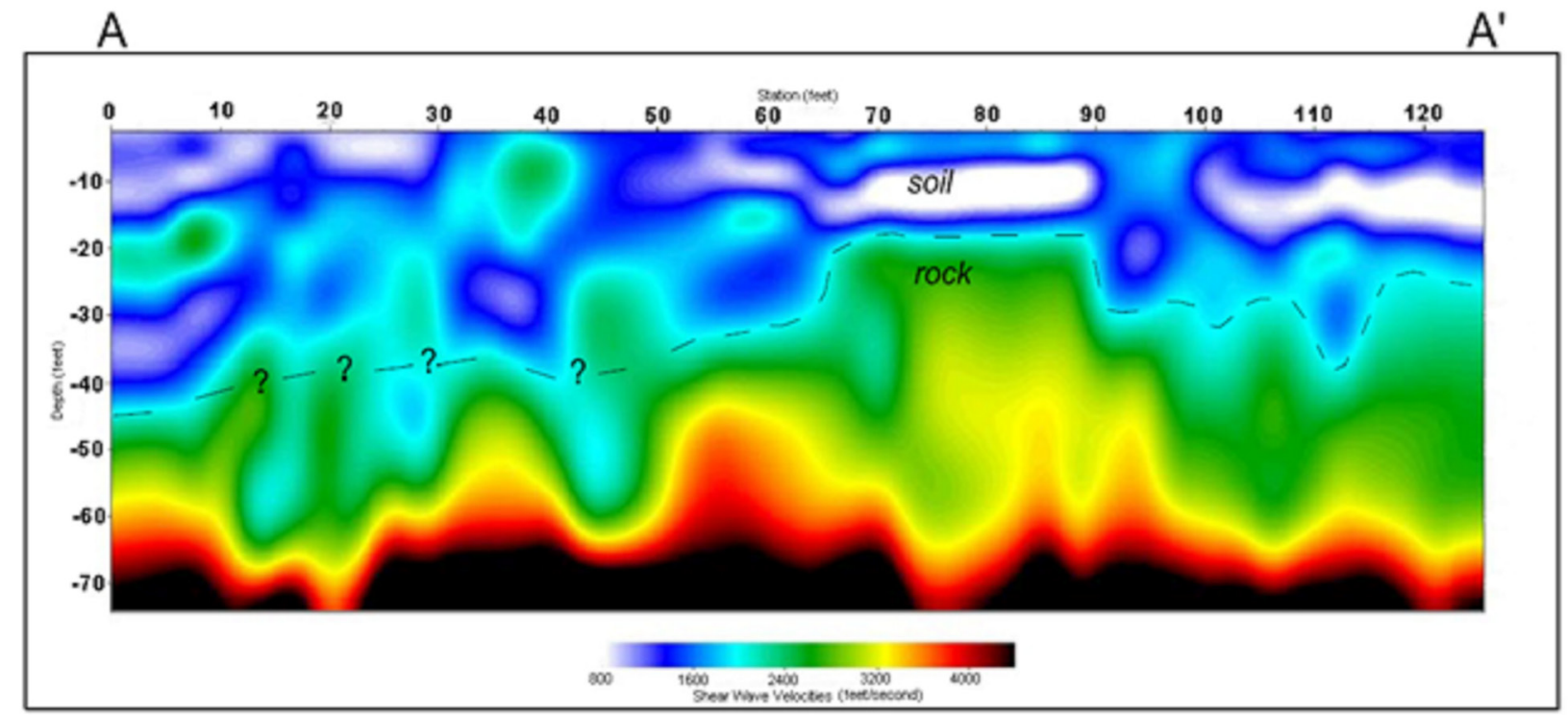

Figure 2. MASW results on western side of creek.

on the bedrock surface, rock coring was performed to evaluate the condition of the underlying bedrock.

As expected from the geophysical testing, the results of the test borings revealed highly variable conditions. The depth to bedrock ranges from seven feet beneath the existing ground surface to in excess of 70 feet (21 meters). The large variation in depth to bedrock exists in two test borings drilled approximately five feet (1.5 meters) apart. Interpretation of a boring drilled near the 2009 sinkhole location and near the pipeline revealed an 11 foot (3.3 meters) continuous void in the bedrock, starting at three feet below the soil/bedrock interface. This void was encountered during the rock coring operation. In areas where subsurface anomalies were found in the geophysical investigation, the test borings confirmed voids in the subsurface. Figure 3 displays the relationship between the results of the microgravity investigation to the conditions found in the borings. The test boring results are displayed on a subsurface profile situated above a plan view of the microgravity results in Figure 3. This figure shows the strong correlation between the two methods and confirms the advantage of using microgravity to determine subsurface conditions.

As a result of the conditions found in proximity to the pipeline by the geophysical investigations and confirmed by the test borings, an emergency "stopgap" grouting operation was performed utilizing a permeation grout. This stopgap grouting program was developed in an attempt to minimize the potential of failure below the pipe while a long-term solution could be determined. A permeation grouting method was chosen based on criteria of attempting to fill voids/fractures in the bedrock as well as minimizing the potential for heaving the active pipeline. The permeation grout consists of a high slump neat cement that can easily flow into fissures and fractures at the soil/bedrock interface. Due to the clayey nature of the overburden soils, grouting was only intended to fill voids in the bedrock. During the grouting, no backpressure was recorded indicating a significant sized void was accepting the grout. A total of 40 cubic yards (12.1 cubic meters) of grout was injected into the subsurface without recorded backpressure.

The results of the geotechnical investigation revealed that active sinkhole conditions were present in the existing pipeline right-of-way. As part of the scope of work, a budgetary value of $\$ 600,000$ was estimated for a remedial grouting operation within the pipeline rightof-way. Due to the extensive voids found in the borings, the large amount of grout required during the stopgap grouting operations, and the potential for extensive active sinkhole conditions near the pipeline, concerns were raised that the grouting costs could easily exceed the budget estimate. Therefore, a subsurface grouting program within the existing right of way was considered to be cost-prohibitive. Furthermore, due to the variable subsurface conditions and depth to competent bedrock found within the right-of-way, a deep foundation system to structurally support the pipeline was not considered viable due to the high costs associated with this option. 


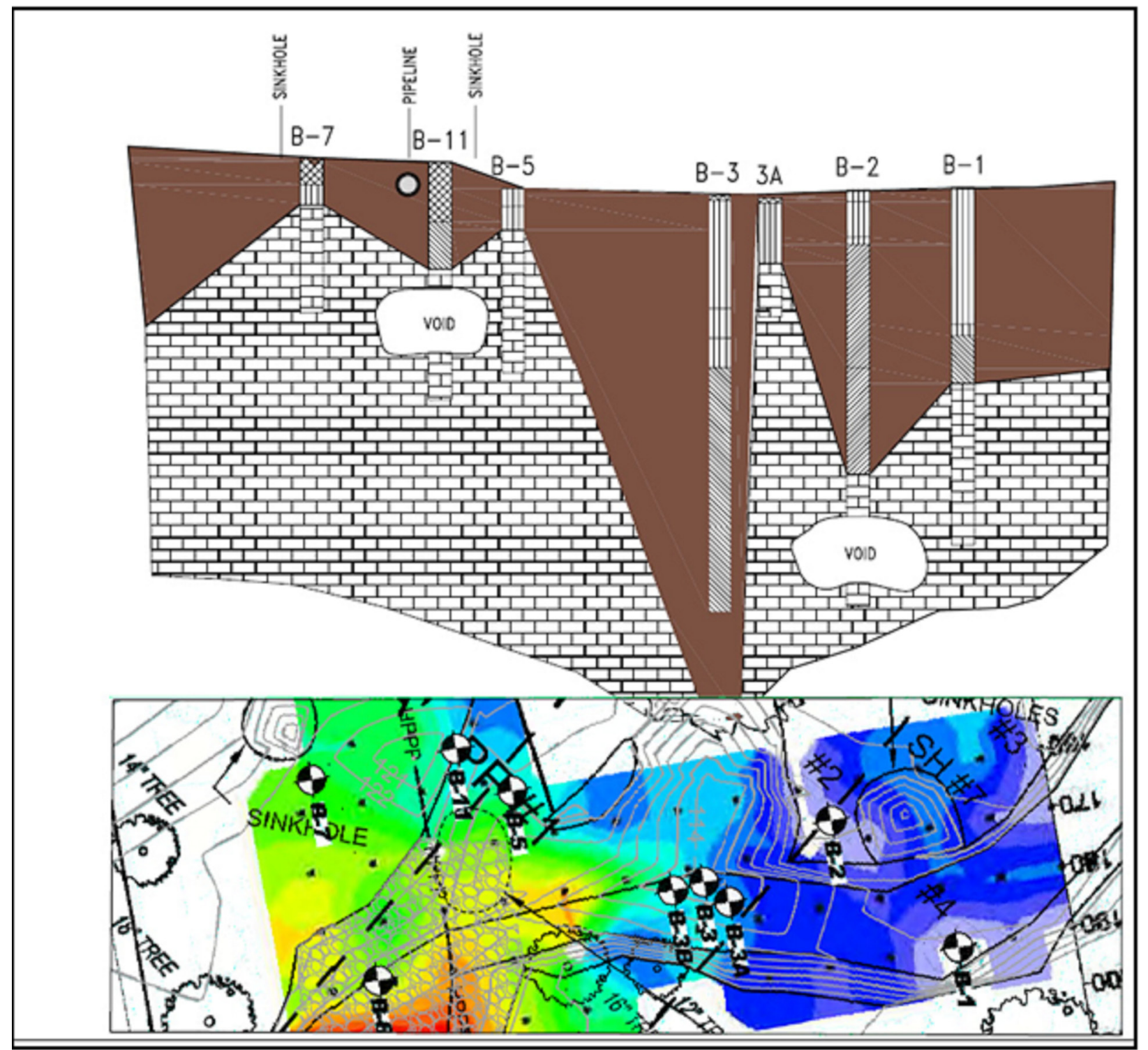

Figure 3. Test boring profiles results and a plan view of the corresponding microgravity results along the creek perpendicular to pipeline.

At that juncture, options to investigate relocating the 400 foot (122 meters) long section of pipeline to a less sinkhole prone location were evaluated. A triangular shaped, undeveloped tract of land is situated directly south of the 400 foot (122 meters) long section of existing pipeline. Once permission was granted to investigate the land to the south, a second phase of work at the site commenced.

Since the purpose of the second phase was to evaluate an optimum route to relocate the pipeline, a proactive approach was taken. The new process consisted of performing an initial microgravity survey in a grid pattern to spatially identify subsurface conditions.
After evaluation of the microgravity results, a proposed pipeline alignment was selected in areas identified with shallow rock and minimal anomalies. Figure 4 displays the results of the microgravity results within the available land to the south of the existing right-of-way and the proposed pipeline relocation route.

After the preferred relocation alignment was chosen, MASW and two-dimensional electrical resistivity (2D ERI) surveys were conducted to provide a linear profile of the subsurface conditions beneath the new alignment. The 2D ERI was used in areas of steep slopes or undulating ground surface. Following the geophysical surveys, test borings were drilled at anomaly locations 


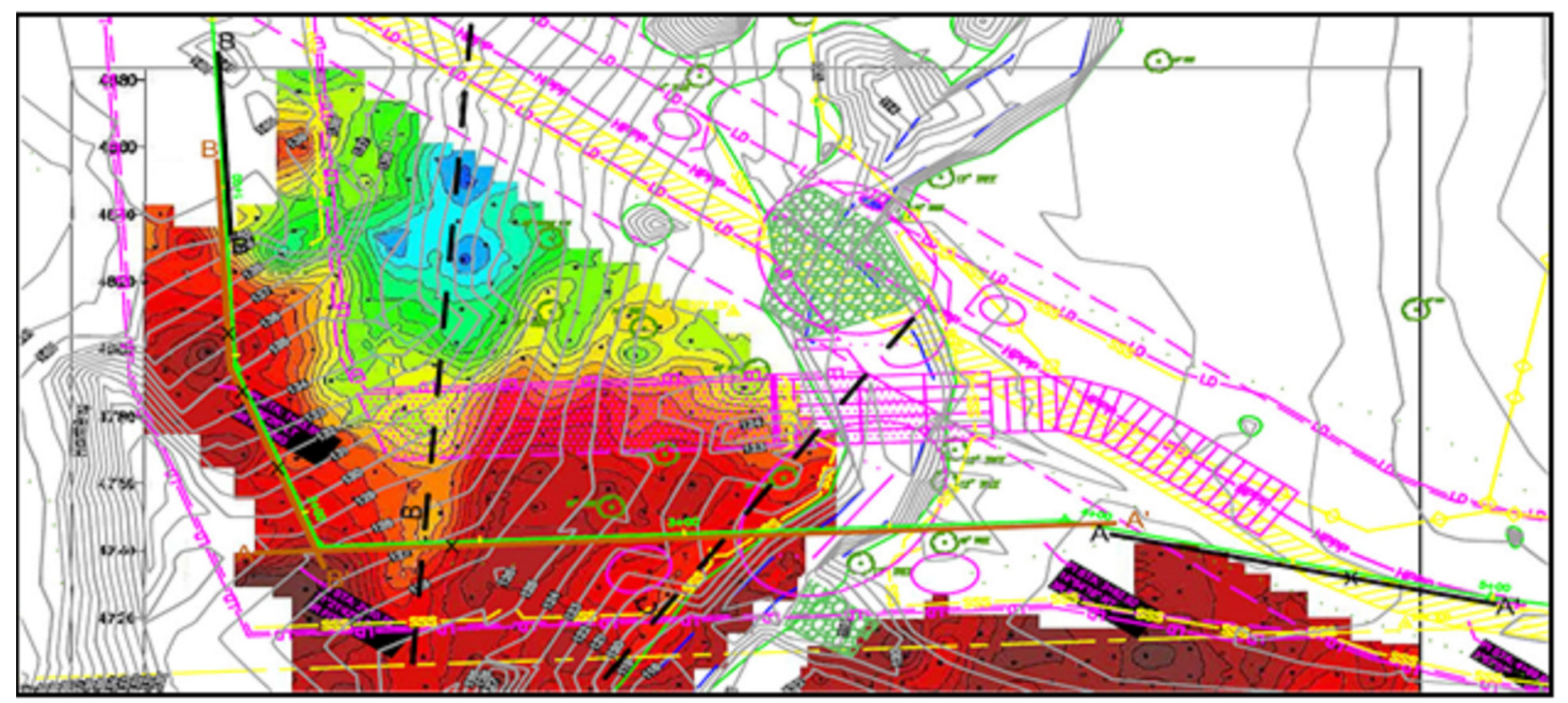

Figure 4. Microgravity results included with MASW \& 2D ERI locations over the proposed realignment route.

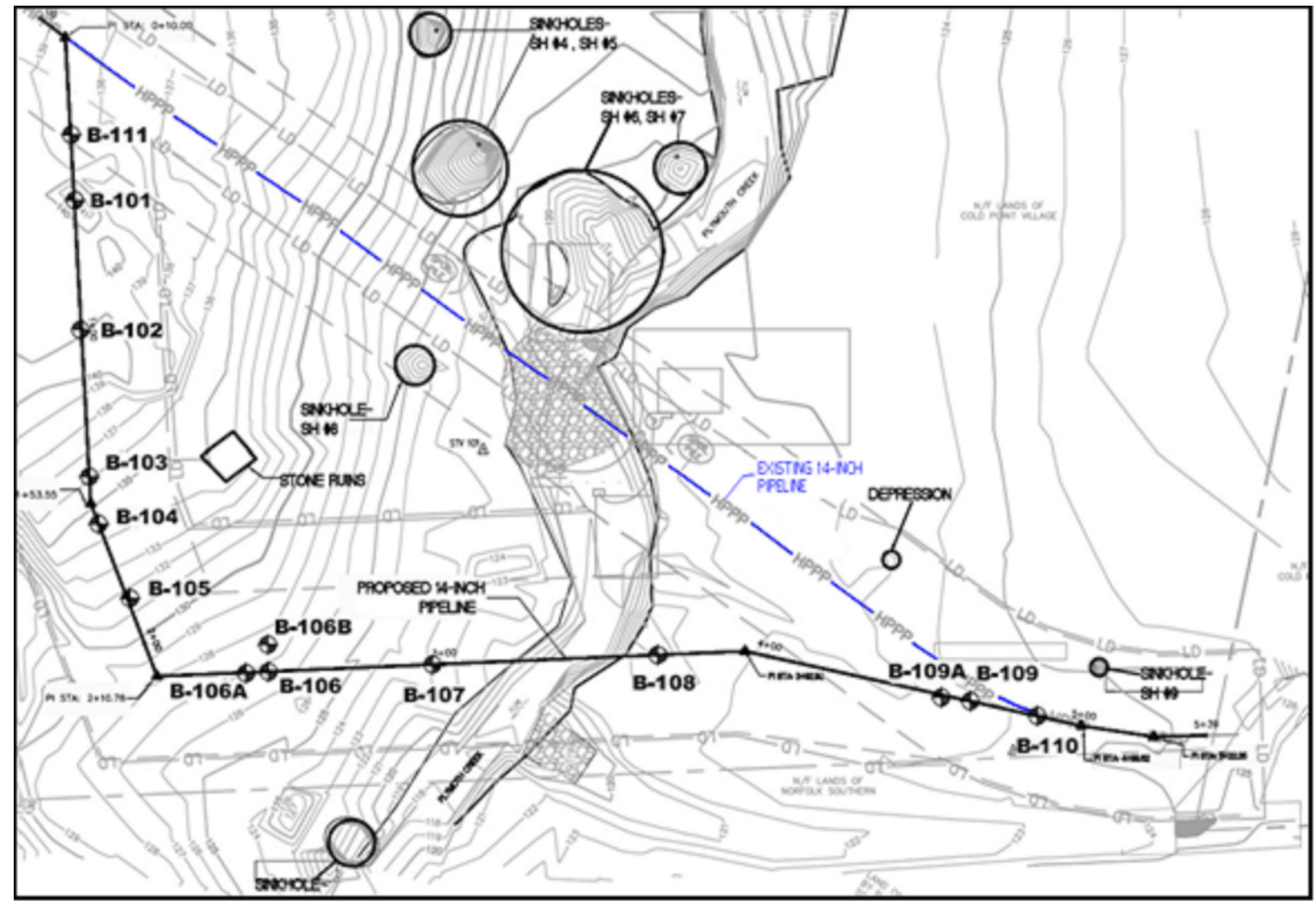

Figure 5. Test boring locations conducted in realignment route. 
identified in the new geophysical testing. Figure 5 displays the test boring locations chosen based on the geophysical testing. Analysis of microgravity data from the new alignment revealed that relatively shallow and dense rock was present with isolated anomalies in most of the new alignment. However, analysis of the 2D ERI and MASW data in the relocated alignment revealed low density bedrock in the initial 70 feet (21.3 meters) of the proposed new pipeline in the vicinity of boring B-111 shown in Figure 5. Additionally, isolated anomalies are located along the remainder of the proposed relocation route. As before, strong correlation was found between the geophysical data and the new boring data.

Within the initial 70 feet (21.3 meters), a medium dense fine grained clayey soil was encountered above the rock surface. However, soil seams, voids and generally poor quality rock were found in the bedrock. Along the remainder of relocation route, some isolated areas of weak soil, voids in the bedrock and poor quality rock exist. Further complicating the new alignment is that poor quality carbonate rock is more susceptible to dissolution and weathering than higher quality rock.

Analysis of the data recorded during the field investigation for the new alignment indicated that a ground modification program is required. The recommended program consists of a subsurface grouting program along portions of the proposed relocation route prior to installation of the new pipeline. The grouting program is required within the initial 70 feet (21.3 meters) of the new pipeline location as well as in areas where the isolated anomalies exist. A grout curtain is to be installed along a portion of the right-ofway where a fracture trace exists. Since sinkholes have a tendency to develop over fractures in the bedrock, the grout curtain is expected to reduce the potential of sinkhole development by cutting off potential flow path(s) in the underlying bedrock.

The recommended subsurface grouting program is based on the level of risk for potential sinkhole formation identified through the geophysical investigations and test boring operation performed. In areas that possess the greatest risk for sinkhole activity, targeted grouting is recommended to be performed in a grid pattern around the identified features. In order to further reduce the risk for sinkhole activity, additional compaction grouting is recommended in between the targeted locations, every 10 feet ( 3 meters) on center below the centerline of the proposed pipeline. Figure 6 displays the proposed grouting location plan.

The grouting program is recommended to be performed in phases. As shown in Figure 6, the black circles display the phase 1 grouting locations and the red triangles display the phase 2 grouting locations. The phase 1 grouting locations consist of installing casing into the bedrock where voids, soil seams, or poor quality bedrock is located. Grouting during the phase 1 operation extends from the voided areas within the bedrock to a depth of 2 feet ( 0.6 meters) below the proposed bottom of trench elevation. During the phase 2 grouting, the casing terminates at the soil/ bedrock interface and extends upward to the same depth criteria referenced for phase 1 . Within the initial zones for each application, a higher slump material is used to allow the grout to permeate into the voids/ fissures and fractures within the bedrock. As the grout casing is raised into the overburden soils, the slump is adjusted to create a low mobility grout similar to compaction grout. The pumping rate is maintained at 1-2 cubic feet per minute $(0.3$ to 0.6 cubic meters per minute) since a high injection rate can cause hydraulic fracturing (Warner, 2004). The grout volume injected per 2 foot ( 0.6 meters) stage is recommended based on the backpressure recorded at the given depths. Table 1 provides the recommended pressure versus grout volumes per 2 foot ( 0.6 meters) stage.

A typical subsurface density profile over carbonate bedrock suggests that the upper crust close to the ground

\begin{tabular}{|c|c|}
\hline TABLE 1. Grout volume cut-off criteria. \\
\hline \hline $\begin{array}{c}\text { Recorded } \\
\text { Backpressure }\end{array}$ & $\begin{array}{c}\text { Volume of Grout } \\
\text { to be Injected }\end{array}$ \\
\hline $0-50 \mathrm{psi}$ & $\begin{array}{c}1.0 \mathrm{yd}^{3} / \mathrm{stage} \\
\left(0.764 \mathrm{~m}^{3} / \mathrm{stage}\right)\end{array}$ \\
$(0-344.7 \mathrm{KPa})$ & $0.5 \mathrm{yard}^{3} / \mathrm{stage}$ \\
& $\left(0.382 \mathrm{~m}^{3} / \mathrm{stage}\right)$ \\
\hline $50-300 \mathrm{psi}$ & $0.25 \mathrm{yard}^{3} / \mathrm{stage}$ \\
$(345-2068 \mathrm{KPa})$ & $\left(0.191 \mathrm{~m}^{3} / \mathrm{stage}\right)$ \\
\hline $300-400 \mathrm{psi}$ & Pressure cut-off - \\
$(2068-2758 \mathrm{KPa})$ & raise to next stage \\
\hline$>400 \mathrm{psi}$ & \\
\hline
\end{tabular}




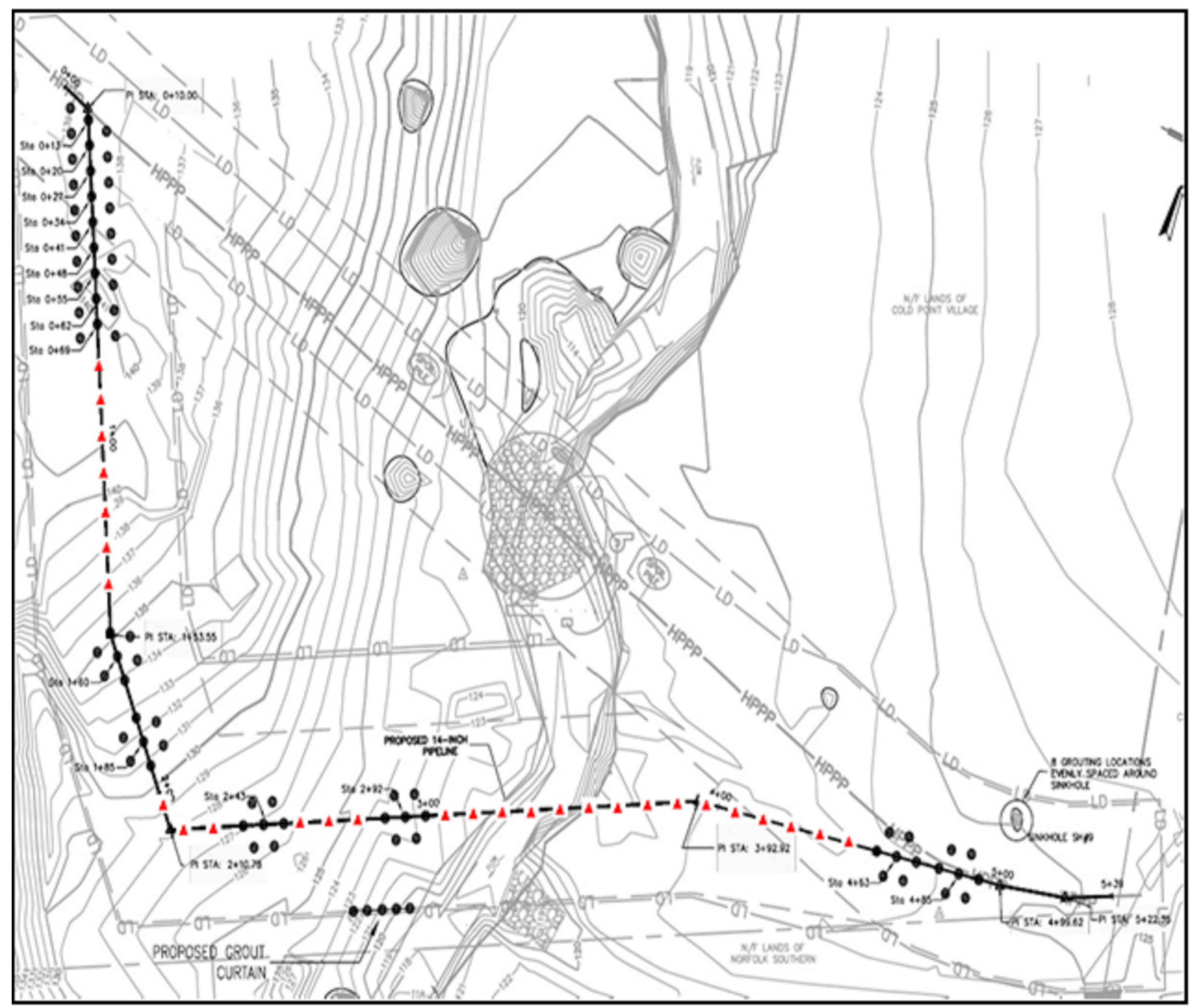

Figure 6. Proposed grouting location plan within realignment route.

surface is typically characterized by stiffer clayey soils. As the depth increases, a decrease in stiffness or density and a gradational change from fine grained to more coarse soils is typically found above the fractured carbonate bedrock surface. When steel casing from the grouting program is installed to the bedrock surface, the grout is expected to flow easier into the typical fissures and fractures at the soil/bedrock surface. The intent is to seal the open "throat" in the rock surface. As the steel casing is raised into the lower zones of the overburden soils, a low mobility displacement grout is used to densify surrounding weak zones of soils and fill any remaining voids that exist near the soil/bedrock interface. Within the zones of the weak soils, it should be expected that the higher volumes of grout will be experienced. As the casing is raised into a denser soil matrix and grouting continues, a decreased volume of grout injection is expected due to the denser soils and higher backpressures. Figure 7 displays the expected results of the recommended grouting operation.

\section{Conclusions}

This paper shows that geophysical testing using microgravity, MASW, and 2D ERI can predict the occurrence of active sinkholes in pinnacled carbonate bedrock. If subsurface grouting is being considered as a method for sinkhole stabilization or treating sinkhole prone site, a comprehensive geophysical and geotechnical investigation will significantly aid in developing an effective scope of work for the project by identifying specific areas and depths requiring ground improvements. The information gathered is also 


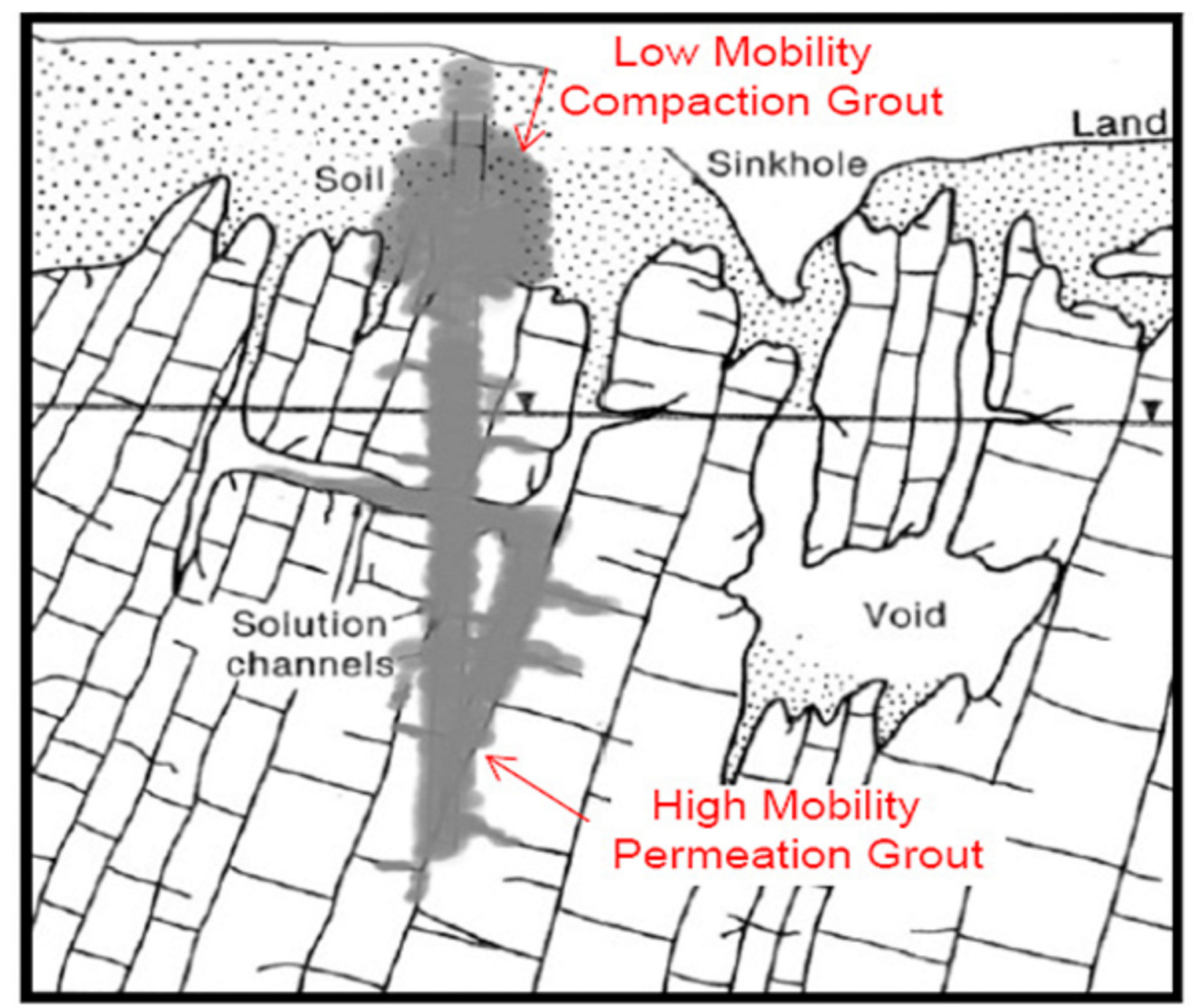

Figure 7. Conceptual sketch of grouting. Base sketch used to show grout from J.P. Wilshusen \& W.E. Kochanov, The Geology of Pennsylvania, 1999.

instrumental in developing a cost estimate for the ground improvement work. Furthermore, by basing the volume injected on the grout backpressure recorded at each stage, a more efficient grouting operation can be expected which may limit the potential for future sinkhole re-occurrence. By engaging a geotechnical engineering firm in the early stages of project development it is possible to provide options to reduce the risks of sinkhole development and reduce costs for potentially problematic sinkhole recurrence.

\section{References}

Lee R, Callahan P, Shelly B, Iqbal A, Kribbs G. 2010. MASW Survey Identifies Causes of Sink Activity Along I-476 (Blue Route), Montgomery County, Pennsylvania. In: GeoFlorida 2010 Conference;

Feb. 20-24.
Lee R. 2010. Continuous Subsurface Profiling of Road Using MASW (multi-channel analysis of surface waves. In: Highway Geology Symposium; August 23-26.

Shultz C, Kochanov W, Wilshusen J. 1999. The geology of Pennsylvania. Pennsylvania Geological Society \& Pittsburgh Geological Society, p.716.

Warner J. 2004. Section 6B: Grouting to improve foundation soil. In: Practical foundation engineering handbook. Available from: McGrawHill digital engineering library http://www. digitalengineeringlibrary.com 
